\title{
NOVAS VERTICALIDADES: APONTAMENTOS SOBRE A AÇÃO DA BMW EM ARAQUARI/SC NO CONTEXTO DO NOVO PADRÃO DE ORGANIZAÇÃO E ACUMULAÇÃO DA INDÚSTRIA
}

\author{
NUEVAS VERTICALIDADES: APUNTES SOBRE LA ACCIÓN DE BMW EN ARAQUARI/SC (BRASIL) \\ EN EL CONTEXTO DEL NUEVO PADRÓN DE ORGANIZACIÓN Y ACUMULACIÓN DE LA INDUSTRIA
}

Palavras-chave: Desenvolvimento territorial; Alienação do território; Verticalidades. .

Palabras clave: Desarrollo territorial; Enajenación del territorio; Verticalidades.

\section{R E S U M O}

No presente artigo analisamos a ação da BMW no município de Araquari no nordeste de Santa Catarina a partir da implantação de uma planta do grupo em 2012. Em que pese o fato de tratar-se de uma região já tradicional na produção industrial, o município acolheu poucas indústrias em sua história, este evento materializa os nexos de um novo vetor capaz de alterar determinadas lógicas locais. Analisamos esse processo no contexto de um novo padrão de organização da indústria nacional representado pela redução do conteúdo local adicionado à produção e no aumento da importação de produtos finais ocorrida nesse início de século. Apontamos o caráter "maquilador" dessa verticalidade que se impõe no lugar e resulta, a partir de dentro, da desvinculação entre a política macroeconômica e a política industrial de um modelo de desenvolvimento difícil de ser apreendido e, a partir de fora, pela expansão sino-americana, crescimento do comércio global das manufaturas e novo arranjo na divisão internacional do trabalho.

\section{R E S U M E N}

En el presente artículo analizamos la acción de BMW en el municipio de Araquari en el noreste de Santa Catarina a partir de la implantación de una planta del grupo en 2012. En que pese al tratarse de una región ya tradicional en la producción industrial, el municipio acogió pocas industrias en su historia, este evento materializa los nexos de un nuevo vector capaz de alterar determinadas lógicas locales. Analizamos este proceso en el contexto de un nuevo estándar de organización de la industria nacional representado por la reducción del contenido local agregado a la producción y en el aumento de la importación de productos finales ocurrida en ese inicio de siglo. Apontamos el carácter "maquilador" de esa verticalidad que se impone en el lugar y resulta, a partir de dentro, de la desvinculación entre la política macroeconómica y la política industrial de un modelo de desarrollo difícil de ser aprehendido y, desde fuera, por la expansión sino americana, crecimiento del comercio global de las manufacturas y nuevo arreglo en la división internacional del trabajo.

\footnotetext{
${ }^{1}$ Mestrando; Universidade Estadual Paulista (Unesp/Rio Claro). E-mail: ruhanb@live.com.

2 Mestranda; Universidade Federal de Uberlândia (UFU). E-mail: ana.pn@live.com.
} 


\section{INTRODUÇÃO}

O atual padrão de desenvolvimento brasileiro tem animado análises sob diversos ângulos da economia e ciência política recentemente. Nos anos 2000, os esforços para entender o crescimento econômico e o desenvolvimento do país foram estimulados pelas mudanças na inserção da economia nacional na divisão internacional do trabalho. Considerando que é a partir do desvelamento da divisão territorial do trabalho que se faz possível desvendar o conteúdo que dá vida às formas geográficas, visto que esta "[...] cria uma hierarquia entre lugares e redefine, a cada momento, a capacidade de agir das pessoas, das firmas e das instituições" (SANTOS; SILVEIRA, 2012, p. 21), este estudo busca analisar a ação da montadora de automóveis BMW, instalada no município catarinense, Araquari.

Situado ao nordeste do estado, Araquari é um pequeno município, cuja participação mais expressiva da indústria no PIB municipal é consideravelmente recente. No estado, a indústria se desenvolveu de forma mais expressiva no Vale do Itajaí e no nordeste do estado, onde se sobressaem os municípios de Blumenau e Joinville, com indústrias de reconhecimento, como: Tupy, Consul, Weg, Embraco, Busscar, Ciser, Shultz e Wetzel.

Durante o processo de crescimento e diversificação do setor industrial no nordeste catarinense, o município de Araquari ocupou uma posição marginal. A economia do município se manteve, em grande medida, marcada pela atividade agrícola, com as culturas de arroz, banana e maracujá, sobretudo. Foi apenas entre o final da década de 2000 e o começo da década seguinte que Araquari passa a ser atrativa para um número significativo de empresas, dentre elas a BMW (Hyosung, Ciser, Fortlev, Jefer e Durín são exemplos de outras que se instalaram no município).

As divisões do trabalho ao se sobreporem evidenciam a disputa pelo território, precisamos saber, portanto, quem em determinadas circunstâncias regula quem nesse embate (SANTOS, 2001). Neste sentido buscamos entender quais os determinantes para a instalação desta indústria no município em questão.

Para tanto, a seguir expomos brevemente algumas leituras sobre a política econômica dos governos do Partido dos Trabalhadores e na sequência discorreremos sobre a ação da montadora BMW no município de Araquari.

\section{PADRÃO DE DESENVOLVIMENTO E ORGANIZAÇÃo E ACUMULAÇÃO DA INDÚSTRIA}

A dificuldade de uma definição certeira das políticas econômicas e sociais dos governos capitaneados pelo Partido dos Trabalhadores se dá em função de sua complexidade e novidade, devido à heterogeneidade dos conteúdos que informaram as políticas, também por isso o número de tentativas de definição ou compreensão. 
No entanto, parece haver consenso na bibliografia em afirmar que Lula cumpriu o compromisso de seu governo com o empresariado (firmado na já bastante citada Carta ao Povo Brasileiro) e atendeu a exigências do mercado quanto à manutenção do tripé macroeconômico herdado dos governos FHC - câmbio flexível, metas de inflação, superávit primário. A lógica neoliberal não é atacada em suas bases, portanto. Ainda assim, a cartilha neoliberal ortodoxa não foi seguida à risca.

De acordo com Bastos (2015) as heresias praticadas pelos governos do PT em relação ao neoliberalismo foram: 1) veto a novas privatizações e restauração da capacidade de investimento das empresas estatais, com destaque para o setor energético; 2) restauração do papel ativo dos bancos públicos na execução de políticas de desenvolvimento produtivo e expansão do mercado interno; 3 ) elevação do salário mínimo real fortalecendo sindicatos e promovendo formalização do emprego, ampliando simultaneamente o conjunto de transferências sociais, notadamente o Bolsa Família.

Segundo Soares (2013) e Druck (2006), embora o governo Lula tivesse uma base popular, ele combinou medidas assistencialistas, desenvolvimentistas e neoliberais, posto que embora tenha investido no setor produtivo (PAC, aumento de recursos para o BNDES, política de isenção fiscal durante a crise econômica), reduziu os direitos trabalhistas com a reforma da previdência e criou de novas modalidades de contratos precários (Pessoa Jurídica (PJ), menor aprendiz) (SOUZA, TRÓPIA, 2016).

De maneira geral é possível afirmar que a partir de 2004 foi retomado o crescimento econômico, o que após a crise de 2007/2008 mudou bruscamente, sobretudo após 2011 (BELLUZZO; BASTOS, 2015): vigorou uma política expansionista até 2010, impulsionada pela dinâmica interna (2006-2010) e pelo setor externo (até 2006), modelo de crescimento que "ficou em cheque" após 2010 (CORREA; SANTOS, 2013).

Entre 2004 e 2011 o Brasil teve uma média de crescimento de 4,3\% ao ano, média que se colocou como menor de vários outros países no período, como China, Índia e Argentina, mas no caso brasileiro, houve crescimento acompanhado de distribuição de renda e redução da pobreza (CORRÊA; SANTOS, 2013).

A rigor, a renda per capita cresceu $25 \%$, o desemprego metropolitano diminuiu $50 \%$ e a pobreza absoluta diminuiu em torno de $50 \%$.

[...] o número de pessoas que viviam com renda abaixo de 70 reais ao mês diminuiu de 17 milhões em 2003 para cerca de 9 milhões em 2009. Também cabe mencionar que a desigualdade da renda pessoal caiu a cada ano - e mais de $10 \%$ no total - entre 2003 e 2009 (CORRÊA; SANTOS, 2013, p. 21).

O nível de inflação, pela política de metas, foi baixo e os ajustes fiscais demandavam controles de gastos. Esta dupla definiu a manutenção da taxa de juros elevada, que como consequência atraiu capitais de curto prazo para o país, valorizando o câmbio. 
Na interpretação de Teixeira e Pinto (2012), o ocorrido durante os anos de governo Lula, foi uma mudança nos fluxos e estoques de riqueza das frações que compõem o bloco no poder. Segundo os autores, neste período o regime de política macroeconômica foi expressão dos movimentos contraditórios presentes no aparelho de Estado. Tais movimentos realizados foram pela fração bancário-financeira nacional e internacional. E o processo que o explica é a taxa de juros praticada.

Explicitando a tese, os autores argumentam que a dinâmica dos fluxos e o estoque de riquezas da grande burguesia produtora e exportadora, entre 1995 e 2007, aumentaram 1.705,9\%. Tal fração ultrapassou a participação da fração bancário-financeira em 2007.

Os embates no interior do bloco no poder necessitam, no entanto, de materialização, o que por sua vez não se pode dar em outro lugar senão no território.

Com a crise de subprime em 2008, a economia brasileira passa por uma desaceleração em 2009, e posteriormente volta a crescer, mas com déficits quanto às transações correntes, até 2010 (CORRÊA; SANTOS, 2013).

Entre o segundo semestre de 2010 e o ano de 2011, as metas de altos níveis de superávits primários foram mantidas, junto com os baixos níveis de inflação e altos juros domésticos. Em geral não se rompeu com o regime de metas. Em 2010, houve a mudança do "mix da política macroeconômica" e do perfil do crescimento do país (CORREA; SANTOS, 2013).

Com a inflação em 4,5\% ao ano, retomou-se a política contracionista, em razão do preço das commodities. Neste ano o país perdeu hegemonia do eixo pró-crescimento, e foi alterada a alavanca do crescimento, pois os investimentos públicos e os gastos das empresas estatais foram alterados.

Alta no ciclo de liquidez internacional, forte crescimento da economia chinesa e crescimento no preço das commodities são os elementos exógenos (CARCANHOLO, 2010), mas o entendimento da conjuntura não pode resumir-se a eles. A direção da política econômica brasileira rumou à perda dos elos produtivos na indústria rumando à substituição por importações.

Assim, o período marca também o aprofundamento do processo de desindustrialização no país, pois além da redução da participação da indústria no PIB (registrado desde a década de 1980) e do baixo dinamismo do setor, a indústria brasileira tem se concentrado no seguimento intensivo em recursos naturais em detrimento de outros com alto valor agregado e alta capacidade de irradiar ganhos para outras cadeias produtivas (DIEGUES; ROSSI, 2017).

O governo Dilma Rousseff, manteve as políticas dos governos Lula e buscou uma nova matriz econômica, uma "guinada industrialista" (SOUZA, 2017).

Para Corrêa e Santos (2013), neste período o objetivo foi tornar as indústrias nacionais uma propulsora para o crescimento, com desonerações fiscais, implementação do Plano Brasil Maior e do estabelecimento de controle de capitais. 
Nos anos seguintes, 2012 e 2013, o apoio a investimentos privados se aprofundou. As medidas praticadas foram à redução na tarifa de energia elétrica, desoneração da folha de pagamento, desonerações fiscais, antecipação do Plano Nacional de Logística Integrada (para financiamentos), subsídios para inovação, redução dos juros e financiamentos via BNDES.

Segundo Souza (2017, p. 6) a partir de Fonseca (2016), as medidas adotadas no governo Dilma, não foram necessariamente desenvolvimentistas e as “[...] renúncias de arrecadação em prejuízo das receitas da União 'talvez tenham virado aplicações financeiras', tendo em vista que os investimentos industriais não ocorreram [...]".

A política de redução de IPI foi realizada pela presidente Dilma Rousseff em 2012 e justificada como mecanismo de manutenção do nível de emprego. A então presidente chegou a cobrar publicamente das empresas, como contrapartida, a manutenção do emprego face denúncias do Sindicato dos Metalúrgicos de São José dos Campos (SP) que pediam a interferência do governo para evitar demissões na General Motors. Segundo a então presidente "[...] 'Damos incentivos fiscais e financeiros e queremos retorno' [...]. 'Não (queremos retorno) para nós, mas para o país inteiro, que é a manutenção do emprego. Damos incentivo para garantir emprego. Eles têm de saber que é por esse único motivo." (VALOR ECONÔMICO, 2012).

Conjunturas de crises são, via de regra, marcadas por desemprego, posto que, para fazer frente a queda da taxa de lucro, o capital investe, como mostrou Marx, contra o trabalho, reduzindo o capital variável.

Ademais, os incentivos nem sempre resultam na manutenção do emprego, que dirá do crescimento de postos de trabalho. Claus Offe (1989) também sustenta que

\begin{abstract}
Mesmo quando se começa com a suposição de que a restauração do pleno emprego não será possível sem o crescimento econômico e, portanto, sem uma elevação no investimento dos empresários, surgem duas questões importantes. Primeiro, ainda que a propensão a investir dos empresários fosse aumentada com êxito, o efeito resultante sobre o emprego poderia ser insignificante, devido ao efeito negativo do investimento em racionalização (microeletrônica), em muitos casos ('crescimento sem emprego'). Segundo, mesmo que seja produzido um efeito positivo sobre o emprego, permanece incerto se os chamados grupos-problema do mercado de trabalho" [indivíduos que dispõe de menor chance de negociar] [...] se beneficiariam e quanto tempo demoraria para que isto acontecesse.
\end{abstract}

Naquela conjuntura de 2012, o capital industrial visando reduzir o impacto da crise na taxa de lucro utilizou de alguns artifícios políticos, além da demissão: contenção salarial, pressão por medidas protetivas ao governo e pressão por financiamento público aos investimentos privados.

Na sequência, o governo Dilma Rousseff teria apostado na existência de espaço político para flexibilizar o tripé macroeconômico. Para Souza (2016), o governo Dilma foi caracterizado por manifestações de empresários contra falta de diálogo, centralização do poder de decisão e aversão ao lucro privado, além de comparações com seu antecessor. Para a autora durante este período houve 
menor investimento em infraestrutura, se comparado ao período anterior, e se apostou em incentivos visando investimentos do setor privado. Ao longo do governo, os industriais foram se afastando de Dilma e se alinhando com os rentistas, da oposição. Entendemos que parte significativa dos grandes industriais brasileiros também é rentista e que, portanto, é difícil determinar que componham frações ou frentes distintas.

0 padrão de organização e acumulação da indústria brasileira foi transformado no período, como defende Diegues (2015, p. 68-69). Segundo o autor, tal padrão estaria embasado:

(i) reorganização das unidades produtivas locais, adequando-as aos novos condicionantes competitivos das redes globais de produção e viabilizando assim a integração essencialmente importadora nessas redes;

(ii) aumento do mercado interno, fomentado pela distribuição de renda, aumento da massa salarial, do emprego e do crédito e

(iii) acoplamento do parque produtivo doméstico ao mercado internacional como grande ofertante de produtos intensivos em recursos naturais.

Nesse sentido, estas transformações têm como resultado o fenômeno denominado de "Doença Brasileira" caracterizada pelas "reconfigurações estruturais na indústria em direção à especialização regressiva e à desindustrialização em paralelo ao surgimento de estratégias que garantem a acumulação do capital investido na esfera industrial" (DIEGUES, 2015, p. 69).

As demandas por liquidez e desempenho a curto prazo imprimem uma concepção financeira das firmas "[...] na qual estas são vistas como um portfólio de subunidades líquidas que devem ser continuamente reestruturadas a fim de que se consiga maximizar o valor acionário da empresa em todos os momentos" (CROTTY, 2002 apud DIEGUES, 2015, p. 15).

A ação da BMW em Araquari pode ser entendida no contexto apontado por Diegues e Rossi (2017): a redução do conteúdo local adicionado a produção resultando no aumento da importação de produtos finais verificada entre 2000 e 2010 pelos autores. A aceitação de tal caráter "maquilador" resulta da desvinculação entre a política macroeconômica e a política industrial como indicado por Bresser-Pereira, Nassif e Feijó (2016).

\section{A AÇÃO DA BMW EM ARAQUARI}

O município de Araquari está localizado no litoral norte de Santa Catarina, conta com uma população de 35.268 habitantes e densidade demográfica de 64,61 habitantes por quilômetro quadrado, segundo estimativa feita pelo IBGE em 2017. Foi entre as décadas de 1970 e 1980 que a população urbana superou a rural em Araquari. No Censo de 1970, 77,94\% da população residia na zona rural, já em 1980, dos 9.674 habitantes do município, 7.384 moravam na zona urbana. 
Mapa 1. Localização de Araquari (SC)

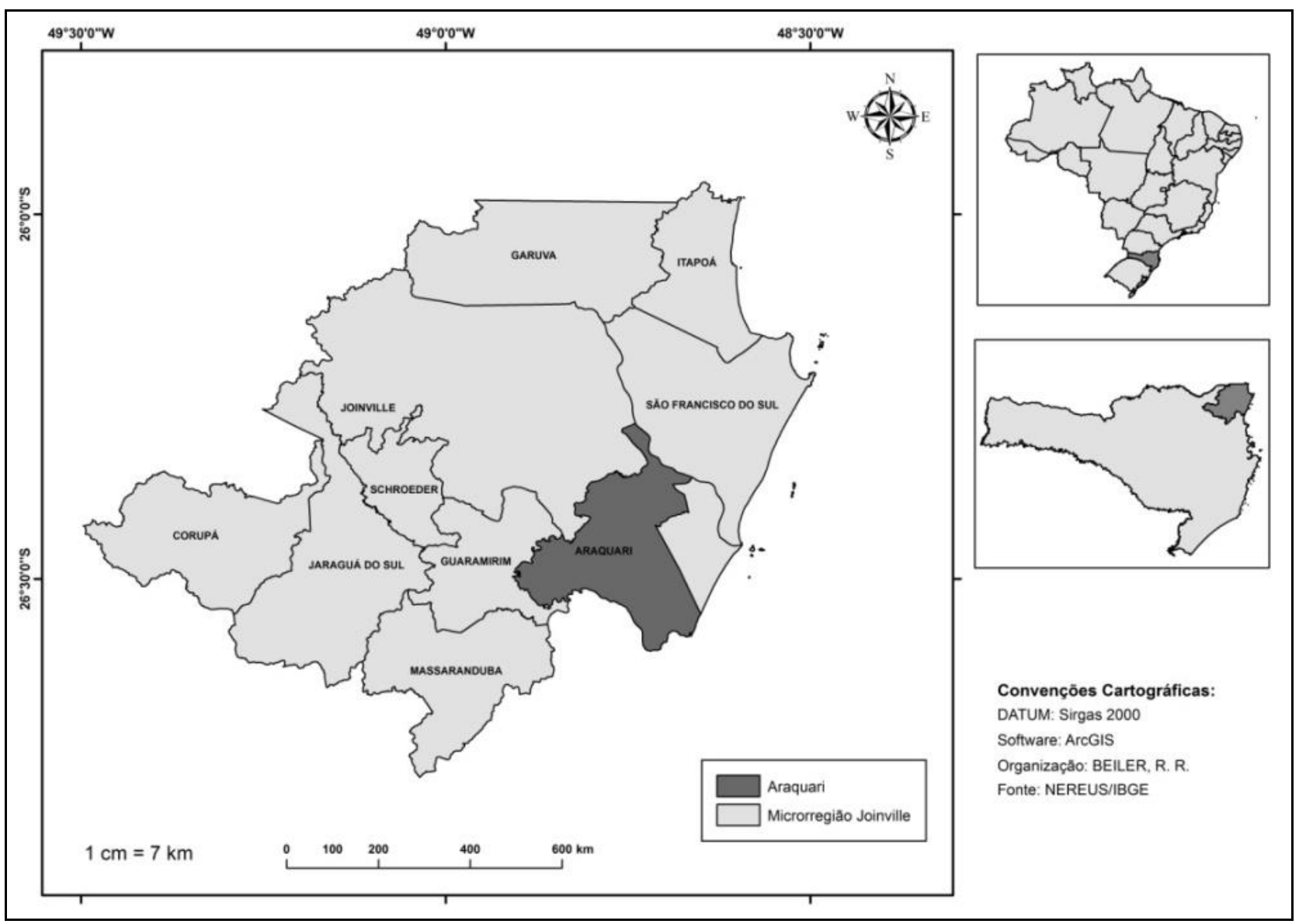

Fonte: Elaboração própria.

O PIB do município era de R\$113.543.000 em 2002 e 2,8 bilhões em 2015, com aumento expressivo a partir de 2010. Em 2015, do total citado, a Indústria foi responsável por $\mathrm{R} \$ 1,1$ bilhões e os Serviços por R \$ 651,9 milhões (IBGE, 2017). 0 gráfico 1 ilustra a composição do PIB do município e o destaque da indústria nos últimos anos. Como demonstraremos, isso se deve à fixação de plantas industriais de grandes empresas na cidade de Araquari.

Esse é um dado novo, no entanto. A participação do município na produção industrial do nordeste catarinense foi marginal, quase inexistente. De modo geral, a região de maior pujança do setor no estado parecia e parece conviver bem com a pobreza araquariense resultante do desenvolvimento espacial desigual.

Em Santa Catarina a indústria se desenvolveu de forma mais expressiva no Vale do Itajaí e no nordeste do estado, onde se sobressaem os municípios de Blumenau e Joinville. Ambos estão localizados em parte de uma das três zonas industriais tipificadas por Mamigonian (1965), a zona de colonização alemã, que reunia, à época, aproximadamente $50 \%$ da produção industrial e $20 \%$ da população (MAMIGONIAN, 1965). 
Nesse sentido, o setor eletro-metal-mecânico no nordeste do estado se consolidou como um dos mais dinâmicos, com destaque para Joinville que, desde a década de 1920, era base de empresas do setor. Mamigonian (1966) afirmou que, em detrimento de outras regiões do estado, a produção industrial em Joinville era bastante diversificada e moderna. Na referida cidade foram fundadas, por exemplo, as empresas: Tupy, Consul, Embraco, Busscar, Ciser, Shultz e Wetzel.

Segundo Rocha (1994, p. 59), nas décadas de 1970 e 1980, “[...] as indústrias joinvilenses, já amadurecidas, investiram na fundação de novas unidades fabris, de suporte para a sua atividade principal ou em outros setores, formando os grandes grupos empresariais e as holdings". 0 destaque, sem dúvida, era a Fundição Tupy, que contou com grandes investimentos e apoio dos governos militares, e estava presente em 875 mil dos um milhão de veículos produzidos pela Volkswagen, em 1970 (TERNES, 1988).

Nesse longo processo de crescimento e diversificação do setor industrial no nordeste catarinense, o município de Araquari ocupou uma posição marginal. A economia do município se manteve, em grande medida, marcada pela atividade agrícola, com as culturas de arroz, banana e maracujá, sobretudo.

0 Índice de Desenvolvimento Humano Municipal (IDH-M) de Araquari reflete, em alguma medida, o cotidiano da maior parte de sua população: em 2000 o município alcançou 0,644, ou seja, a 224aa posição estadual no indicador (dentre os 295 municípios de Santa Catarina).

É apenas entre o final da década de 2000 e o começo da década seguinte que Araquari passa a ser atrativa para um número significativo de empresas, dentre elas a BMW (Hyosung, Ciser, Fortlev, Jefer e Durín são exemplos de outras que se instalaram no município).

Gráfico 1. Composição do PIB de Araquari - 2002-2015



Fonte: IBGE - SIDRA (2018). Elaboração própria. 
Em 2012, o BMW Group confirmou oficialmente que instalaria uma planta no município de Araquari, o que se concretizou com a inauguração em 2014. De acordo com o grupo (BMW, 2017), foram investidos mais de $\mathrm{R} \$ 600$ milhões (a maior parte concedidas via incentivos estaduais), para a instalação da fábrica, com capacidade para produzir 32 mil carros de luxo por ano. Além da BMW, o grupo alemão detém as marcas Mini e Rolls-Royce Motor e teve em 2016 um lucro de 7,25 bilhões de dólares.

Esta verticalidade que se impôs em Araquari é a materialização da lógica global sobre o lugar:

O espaço global não existe a não ser como possibilidade, como essência, como estrutura que se concretiza, isto é, torna-se existência exatamente no momento do impacto das novas relações sobre as formas precedentes. Assim visto, como uma estrutura em processo de totalização, o espaço global ganha força explicativa e significação, à medida que buscamos identificar no lugar a forma e dimensão de sua manifestação, descobrindo as regras, os nexos, as lógicas de transformação pelas quais está constantemente sendo reestruturado. Em função da coexistência dessas lógicas, isto é, a lógica global e a lógica local, é que se produz no lugar um novo arranjo territorial, cuja dinâmica é ritmada pelo conjunto das possibilidades concretas que tem modificado a relação entre o lugar e o mundo (KAHIL, 2005, p. 7195).

A verticalidade se impõe. E a vida de relação, a exploração do trabalho vivo nos limites do município passa a ter nexos mais distantes e mais alienantes. Os dados da balança comercial nos ajudam a compreender estas ligações. Em 2005, tanto exportações quanto importações, estiveram na casa de US\$ 1 milhão, ao passo que em 2010 as exportações foram de US\$ 3,7 milhões e as importações na casa dos US\$ 55,5 milhões, já em 2016, as exportações e importações foram de, respectivamente, US\$257,8 milhões e US\$357,4 milhões.

Gráfico 2. Balança comercial de Araquari (US\$ em milhões) - 2003-2017

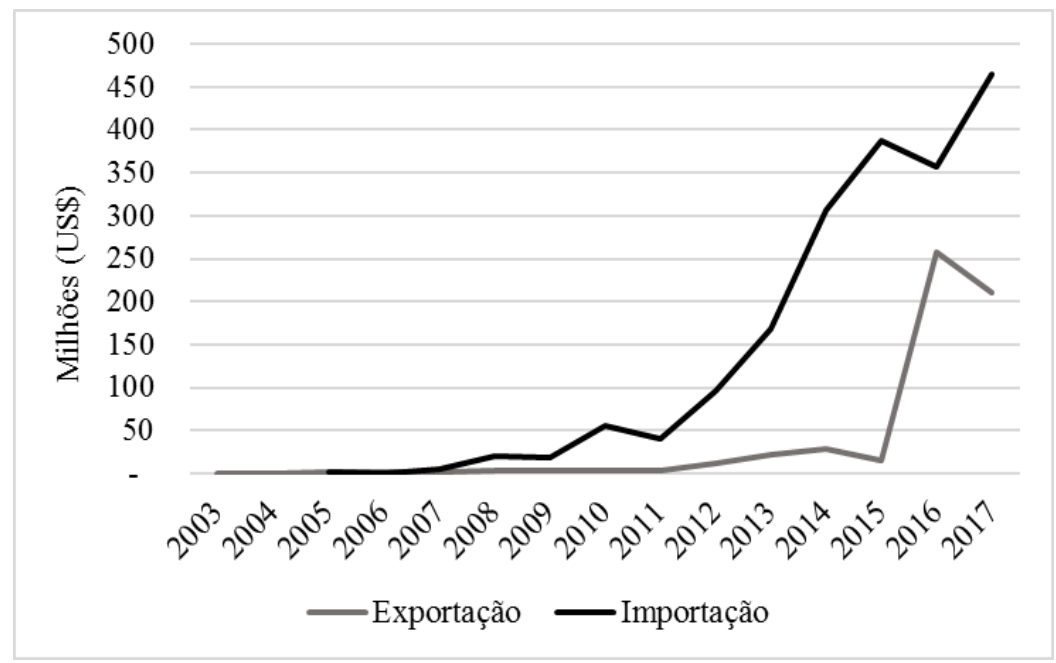

Fonte: MDIC - SECEX (2018). Elaboração própria. 
Em 2005 houve predomínio dos bens de consumo não duráveis nas exportações (mais de 90\%) correspondente às bolachas e biscoitos exportados ao Uruguai, destacadamente; no que diz respeito às importações, a totalidade foi de bens intermediários, no caso, substâncias químicas de uso industrial vindo predominantemente da Rússia. Em 2010 as bolachas e biscoitos continuam tendo destaque nas exportações (58,8\% do valor), tendo como destino Angola e Uruguai, sobretudo; e as importações continuam com destaque dos insumos industriais vindos do Chile e Coreia do Sul, em sua maior parte. Estes fluxos eram comandados pelo grupo Mabel e seu carro-chefe Biscoitos Mabel (hoje pertencente à transnacional Pepsico), com planta em Araquari entre 2004 e 2013.

Tabela 1. Exportações de Araquari por total agregado (US\$) - 2003-2017

\begin{tabular}{crrr}
\hline Ano & Básicos & Semimanufaturados & Manufaturados \\
\hline 2003 & - & - & 13.550 \\
2004 & - & - & 14.351 \\
2005 & - & - & 1.079 .807 \\
2006 & - & - & 1.379 .335 \\
2007 & 418 & - & 1.883 .523 \\
2008 & - & - & 3.645 .742 \\
2009 & - & - & 2.539 .807 \\
2010 & - & - & 3.708 .365 \\
2011 & - & - & 3.398 .765 \\
2012 & - & - & 12.006 .074 \\
2013 & - & 24.645 & 21.025 .990 \\
2014 & 1.124 .852 & 525 & 26.860 .061 \\
2015 & 2.320 .604 & 46.200 & 13.287 .079 \\
2016 & 2.912 .854 & 63.018 & 254.863 .757 \\
2017 & 3.107 .729 & 4.664 .296 & 202.827 .605 \\
\hline \multicolumn{4}{c}{ Fonte: MDIC - SECEX (2018). Elaboração própria. }
\end{tabular}

Tabela 2. Importações de Araquari por total agregado (US\$) - 2003-2017

\begin{tabular}{cccc}
\hline Ano & Básicos & Semimanufaturados & Manufaturados \\
\hline 2005 & 75.646 & 200.047 & 730.013 \\
2006 & 90.086 & - & 140.151 \\
2007 & - & 343.622 & 4.934 .624 \\
2008 & - & - & 20.442 .261 \\
2009 & 172 & - & 19.174 .129 \\
2010 & 431 & - & 55.495 .721 \\
2011 & - & - & 40.514 .541 \\
2012 & 349 & - & 96.472 .841 \\
2013 & 3.717 & 407.108 & 168.140 .218 \\
2014 & 78.393 & 414.445 & 306.087 .305 \\
2015 & 13.094 & 70.086 & 386.476 .179 \\
2016 & - & 123.261 & 357.266 .178 \\
2017 & 328.329 & 1.654 .344 & 463.561 .607 \\
\hline \multicolumn{5}{c}{ Fonte: MDIC - SECEX (2018). Elaboração própria. }
\end{tabular}


Já em 2016, a mudança dos fluxos das trocas se mostrou significativamente distintos. Naquele ano 93,1\% do total exportado correspondeu aos automóveis, enviados todos aos EUA; as importações passam a ser partes e acessórios de veículos, motores de pistão, laminados etc, vindos da Alemanha (39\%) e China (16,7\%), destacadamente. Em 2017 o valor das exportações cai, mas o destino principal continua sendo os EUA. Quanto às importações, Alemanha e China continuam fornecendo a maior parte dos produtos $(28,8 \%$ e $13,8 \%$ respectivamente) e os EUA tem sua participação aumentada, foram 45,9 milhões de dólares (9,8\%).

A mudança no conteúdo dos fluxos de mercadorias e no valor das transações muito se deve à atuação de novos agentes no território, destacadamente a BMW, mas também a Hyosung e mais recentemente a Ciser, dentre outros. Essas relações expressam também a divisão territorial do trabalho.

Parece claro o caráter "maquilador" da planta da BMW em Araquari: parte significativa das peças vêm da Alemanha e China, os carros de luxo são montados e vendidos todos aos Estados Unidos. O lugar figura apenas como ponto explorado. Não há transferência de tecnologia e nem mesmo o efeito que se a atração de fornecedores e aquecimento do consumo produtivo em elos mais curtos, horizontais, se deu na dimensão alardeada pela imprensa local.

Movimento parecido foi percebido no interior de São Paulo recentemente, Toyota em Porto Feliz, Honda em Itirapina e Mercedes-Benz em Iracemápolis, todos municípios com menos de 50 mil habitantes quando da instalação das plantas industriais (SAMPAIO, 2013), o que indica que não é exclusividade do município de Araquari a atração de tais atividades. A guerra fiscal, já menos alardeada que nos anos 1990, continua ocorrendo e os únicos beneficiários parecem ser as grandes empresas, já que o território municipal é alienado.

Além disso, os dados mostram que, a despeito de ter ficado à margem do processo de industrialização pesada, o que na região nordeste do estado diz respeito às indústrias metalmecânicas, do setor elétrico, do plástico e mecânicas, grosso modo, na primeira década do século XXI o município de Araquari passa a receber grandes indústrias nacionais e estrangeiras, em um período distinto daquele ocorrido em Joinville, Blumenau, Jaraguá do Sul, por exemplo.

Em 2002 o setor que mais empregava no município era o de Serviços, com 1005 trabalhadores, seguido pela Indústria, que empregava 624 trabalhadores. No ano de 2016, os empregados na Indústria eram 5071, e nos Serviços 1924 trabalhadores, segundo dados do RAIS (MTE, 2016). Também o número de estabelecimentos industriais salta de 28 em 2002 para 370 em 2016. Esses dados (detalhados abaixo) mostram a significativa mudança na estrutura produtiva pela qual passou o município dos últimos dez anos sobretudo. 
Tabela 3. Número de estabelecimentos em Araquari por setor - 2002-2016

\begin{tabular}{lrrrrrrrr}
\hline IBGE Setor/Ano & 2002 & 2004 & 2006 & 2008 & 2010 & 2012 & 2014 & 2016 \\
\hline Extrativa Mineral & 5 & 5 & 7 & 6 & 9 & 10 & 10 & 13 \\
$\begin{array}{l}\text { Indústria de } \\
\text { Transformação }\end{array}$ & 28 & 31 & 52 & 92 & 162 & 236 & 316 & 370 \\
$\begin{array}{l}\text { Serviços Industriais } \\
\text { de Utilidade Pública }\end{array}$ & 1 & 0 & 1 & 1 & 2 & 4 & 3 & 6 \\
Construção Civil & 5 & 6 & 7 & 10 & 27 & 57 & 76 & 69 \\
Comércio & 49 & 66 & 89 & 119 & 169 & 223 & 286 & 345 \\
Serviços & 41 & 47 & 65 & 93 & 117 & 196 & 261 & 292 \\
Administração Pública & 2 & 3 & 2 & 3 & 4 & 4 & 4 & 4 \\
Agropecuária, Extração & 22 & 23 & 35 & 32 & 32 & 29 & 23 & 20 \\
Vegetal, Caça e Pesca & 153 & 181 & 258 & 356 & 522 & 759 & 979 & 1119 \\
Total & Fonte: MTE - RAIS (2018). Elaboração própria. & & & \\
\hline \multicolumn{7}{c}{} \\
\end{tabular}

Tabela 4 Número de trabalhadores empregados em Araquari por setor - 2002-2016

\begin{tabular}{|c|c|c|c|c|c|c|c|c|}
\hline IBGE Setor & 2002 & 2004 & 2006 & 2008 & 2010 & 2012 & 2014 & 2016 \\
\hline Extrativa mineral & 53 & 62 & 66 & 70 & 195 & 229 & 232 & 296 \\
\hline $\begin{array}{l}\text { Indústria de } \\
\text { transformação }\end{array}$ & 624 & 830 & 966 & 1267 & 2393 & 3409 & 5002 & 5175 \\
\hline $\begin{array}{l}\text { Servicos industriais de } \\
\text { utilidade pública }\end{array}$ & 0 & 0 & 9 & 9 & 14 & 40 & 43 & 63 \\
\hline Construção Civil & 18 & 21 & 20 & 169 & 216 & 286 & 457 & 1036 \\
\hline Comércio & 473 & 616 & 679 & 691 & 932 & 1275 & 1770 & 1695 \\
\hline Serviços & 1005 & 845 & 885 & 1165 & 1703 & 2331 & 2540 & 1924 \\
\hline Administração Pública & 320 & 403 & 446 & 453 & 521 & 701 & 914 & 755 \\
\hline $\begin{array}{l}\text { Agropecuária, extração } \\
\text { vegetal, caça e pesca }\end{array}$ & 131 & 109 & 130 & 179 & 212 & 137 & 122 & 144 \\
\hline Total & 2624 & 2886 & 3201 & 4003 & 6186 & 8408 & 11080 & 11088 \\
\hline
\end{tabular}

Fonte: MTE - RAIS (2018). Elaboração própria.

A instalação da planta industrial da BMW em Araquari contou com atuação forte do Estado. Sabemos com Santos $(2004,1999)$ que a lógica da competitividade também se mostra entre unidades da federação e municípios, de modo que "[...] cada lugar entra na contabilidade das empresas com diferente valor".

Samira Peduti Kahil (2005, p. 7198) apreende tal articulação quando afirma que: "[...] diante da impaciência das empresas e das regiões, o poder público promove um rearranjo do conteúdo normativo para viabilizar o aumento da produtividade espacial e tornar mais eficiente o uso do território, pois é mais rápido mudar o arranjo jurídico que o arranjo material”.

A BMW figura como um exemplo de empresa que lucra com tais arranjos. A empresa beneficiou-se do programa federal Inova-Auto (Lei n 12.715/2012), do Programa Pró-Emprego (Lei 
no 13.992/2007) e do Programa de desenvolvimento da empresa catarinense - PRODEC (Lei no 13.342/2005) em âmbito estadual e de diversas concessões municipais expressas pelo Decreto no $37 / 2013$.

0 primeiro concede $30 \%$ de abatimento do IPI, o segundo assegura tratamento tributário diferenciado do ICMS além de ter concedido financiamento de R\$240 milhões via BRDE (Banco Regional de Desenvolvimento) a partir de captação junto ao BNDES, o terceiro concedeu financiamento de R $\$ 200$ milhões (usados para compra de terreno e infraestrutura básica) via BADESC (Agência de Fomento do Estado de Santa Catarina), já o decreto municipal supracitado, isentou o ISS sobre todos os serviços direta ou indiretamente ligados à construção da planta (desde a escolha do local, planejamento até o começo das atividades), incluindo contratados e subcontratados nacionais ou estrangeiros; cobrança do ISS a uma alíquota de no máximo de 2\% por 15 anos, a partir do início das operações; isenção de IPTU por 15 anos; isenção de ITBI por 15 anos; isenção de toda e qualquer taxa municipal por 15 anos (NOTÍCIAS DO DIA, 2014; PREFEITURA MUNICIPAL DE ARAQUARI, 2016).

Ademais, pesa a favor do município o fato de estar localizado muito próximo ao porto de São Francisco do Sul, município vizinho, e também é próximo aos portos de Navegantes, Itajaí, Itapoá e Paranaguá. Foi por este último, aliás, que a BMW começou a exportar seus veículos do novo modelo BMX X1 aos Estados Unidos. A escolha se deu pelos serviços diferenciados que o porto oferece para esse tipo de carga (A Notícia, 2016).

Duas rodovias federais cortam o município, a BR-101 e a BR-280. Estes são fatores que garantem o escoamento da produção, uma condição que, certamente, é levada em conta na instalação dos empreendimentos. 0 município passa a receber grandes empresas, sobretudo, após 2007. São exemplos dessa instalação recente as empresas: BMW, Hyosung, Ciser, Fortlev, Jefer e Durín. E a prefeitura continua recebendo pretendentes (estrangeiros e nacionais) desejosos de se instalarem no município.

Dessa forma, é muito provável que esses grupos tenham escolhido Araquari também pela proximidade com Joinville, município mais populoso e industrializado de Santa Catarina. De qualquer forma, o crescimento do número de estabelecimentos e de trabalhadores empregados na indústria nos últimos anos, em termos relativos, é expressivo.

Assim, as verticalidades se impõem às horizontalidades a partir do acionamento do território de Araquari como ponto de interesse de alguns agentes hegemônicos. Assim, o território municipal passa a compor a rede destes agentes e através dela ser comandado por normas distantes do lugar. Como afirma Pereira (2011, p. 100): "Se o resultado do trabalho realizado num lugar não se reverte em benefício do próprio lugar, se não pertence ao próprio lugar, e se as atividades no território nacional não são feitas em função das suas próprias carências [...], temos, de fato, um território alienado [...]”. 


\section{CONSIDERAÇÕES FINAIS}

O caso de Araquari é um exemplo da alteração do conteúdo e do valor das normas vigentes no lugar a partir da imposição dos novos objetos e formas organizacionais por grandes empresas. Cria-se uma viabilidade territorial; uma psicosfera de caráter desenvolvimentista (mas com intenções entreguistas), vale dizer uma alienação territorial; que, por fim, acaba por constituir-se em verdadeira alienação do território.

Assim, a adequação normativa do lugar em função de interesses externos acaba por ser um imperativo. É por meio de agentes destacados da economia e da política local que os agentes do circuito superior da economia aparecem como soluções para os problemas do território. No entanto, como já afirmamos, estas verticalidades só podem acirrar os problemas, pois só o que as interessa são os recursos capazes de gerar lucro.

\section{REFERÊNCIAS}

BASTOS, Pedro Paulo Zahluth. Austeridade para quem? A crise global do capitalismo neoliberal e as alternativas no Brasil. Texto para Discussão, v. 257, IE Unicamp, 2015.

BELLUZZO; Luiz Gonzaga; BASTOS, Pedro Paulo Zahluth. Introdução: Austeridade para quem?. In:___. (Org.). Austeridade para quem? balanço e perspectivas do governo Dilma Rousseff. São Paulo: Carta Maior; Friedrich Ebert Stiftung, 2015.

BMW. BMW. Celebrando 2 anos de fábrica no Brasil. Uma fábrica construída, muitos sonhos realizados. Disponível em: <https://www.bmw.com.br/pt/topics/fascination -bmw/fabrica/fabrica.html>. Acesso em 4 ago. 2018.

BRESSER-PEREIRA, Luiz Carlos; NASSIF, André; FEIJÓ, Carmem. A reconstrução da indústria brasileira: a conexão entre o regime macroeconômico e a política industrial. Revista de Economia Política, v. 36, n. 3, p. 493-513, 2016.

CARCANHOLO, Marcelo Dias. Inserção externa e vulnerabilidade da economia brasileira no governo Lula. In: MAGALHÃES, J. P. A. et al. Os anos Lula: contribuições para um balanço crítico. São Paulo: Ed. Garamond, 2010.

CORRÊA, Vanessa. Petrelli.; SANTOS. Claudio Hamilton. Modelo de crescimento brasileiro e mudança estrutural? avanços e limites? In: CORRÊA, Vanessa. Petrelli. (Org.). Padrão de Acumulação e desenvolvimento brasileiro. São Paulo: Ed Fundação Perseu Abramo, 2013, v. 1.

DIEGUES, Antônio Carlos; ROSSI, Caroline Gut. Além da desindustrialização: transformações no padrão de organização e acumulação da indústria em um cenário de 'Doença Brasileira'. Texto para Discussão, v. 291, IE Unicamp, 2017.

DRUCK, Graça. Os Sindicatos, os Movimentos Sociais e o Governo Lula: Cooptação e Resistência. Observatório Social de América Latina, Buenos Aires, v. VI, n. 19, jul 2006, p. 329-340.

KAHIL, Samira Peduri. Usos do território: uma questão política. X Encontro de Geógrafos da América Latina. São Paulo: USP. 2005. p. 71937204.

MAMIGONIAN, Armen. Estudo Geográfico das Indústrias de Blumenau. Revista Brasileira de Geografia, Rio de Janeiro, p. 63-155, jul./set. 1965.

MAMIGONIAN, Armen. Vida Regional em Santa Catarina. Orientação, São Paulo, n. 2, set.1966.

OFFE, Claus. Trabalho e Sociedade: Problemas estruturais e Perspectivas para o Futuro da 'Sociedade do Trabalho'. Vol I, A Crise. Rio de Janeiro: Edições Tempo Brasileiro, 1989.

PEREIRA, Mirlei Fachini Vicente. Território e política: práxis invertidas e desafios da existência. Sociedade \& Natureza, Uberlândia, v. 23, n. 1, p. 95-104, abril 2011.

POCHMANN, Marcio. 0 trabalho na crise econômica no Brasil: primeiros sinais. Estudos avançados, v. 23, n. 66, p. 41-52, 2009.

ROCHA, Isa. O. Industrialização de Joinville (SC): da gênese às exportações. (1994) Dissertação (Mestrado) - Curso de Pós-Graduação em Geografia, Universidade do Estado de Santa Catarina, Florianópolis, 1994. 
SAMPAIO, Lucas. Grandes industrias, pequenas cidades. Folha de São Paulo [online]. Disponível em:

<http://www1.folha.uol.com.br/fsp/mercado/14 0448-grandes-industrias-pequenascidades.shtml>. Acesso em 01 ago. 2018.

SANTOS. Milton; SILVEIRA, Maria Laura. O Brasil: território e sociedade no início do século XXI. Rio de Janeiro: Record, 2012.

SANTOS, Milton. Guerra dos lugares. Folha Online. 8 ago. 1999. Disponível em: < http://www1.folha.uol.com.br/fol/brasil500/dc_3 _5.htm>. Acesso em 16 ago. 2017.

SANTOS, Milton. O Território e o Saber Local: algumas categorias de análise. Cadernos IPPUR, Rio de Janeiro, Ano XIII, n. 2, 1999b, p. 15-26.

SANTOS, Milton. Por uma outra globalização: do pensamento único à consciência universal. Rio de Janeiro: Record, 2004.

SOUZA, Angelita Matos. Governos do PT: Dependência e Desenvolvimento. In: 9o Congresso Latino-Americano De Ciência Política (Alacip), 2017, Montevideu. Trabajos presentados. Montevideu: ALACIP, 2017.

SOUZA, Angelita. Matos. Arriscando uma compreensão do primeiro governo Dilma. In: XXI Encontro Nacional de Economia Política, 2016, São Bernardo do Campo, UFABC. Economia Política da Recessão, 2016.

SOUZA, Davisson Charles Cangussu de.; TRÓPIA, Patrícia Vieira. Greves, conjuntura políticoeconômica e transformações ideológicas no sindicalismo brasileiro recente (1989-2013). In: III International Conference Strikes and Social Conflicts: Combined historical approaches to conflict., 2016, Barcelona.

TEIXEIRA, Rodrigo Alves; PINTO, Eduardo Costa. A economia política dos governos FHC, Lula e Dilma: dominância financeira, bloco no poder e desenvolvimento econômico. Economia $e$ sociedade, v. 21, n. Especial, 2012.

TERNES, Apolinario. A estratégia da confiança: Fundição Tupy: História. 2. ed. Joinville, 1988.

VALOR ECONÔMICO. Dilma cobra manutenção de emprego como contrapartida a incentivo. [online]. jul. 2012. 